\title{
The Acute Metabolic and Hemodynamic Responses of the Left Ventricle to Ethanol *
}

\author{
Timothy J. Regan, $†$ Gabriel Koroxenidis, Christos B. Moschos, Henry A. \\ Oldewurtel, Patrick H. Lehan, and Harper K. Hellems \\ (From the Department of Medicine, New Jersey College of Medicine, Thomas J. White \\ Cardiopulmonary Institute, and B.S. Pollak Hospital for Chest Diseases, \\ Jersey City, N.J.)
}

Although ethyl alcohol has a long medicinal history (1), its precise effects on the cardiovascular system have not been defined. Acute alcohol ingestion is known to result in triglyceride accumulation in the liver, which appears dependent upon an intact sympathetic nervous system (2). Evidence for stimulation of this system after ethanol ingestion has been advanced (3). Since sustained catecholamine infusion has been associated with lipid accumulation in the myocardium $(4,5)$, a study of the acute effects of ethanol on myocardial metabolism and function has been undertaken in animals considered nutritionally normal. The quantity given produced blood level concentrations usually associated with moderate intoxication.

\section{Methods}

Mongrel male dogs weighing 19 to $22 \mathrm{~kg}$ were anesthetized 18 hours postprandially with morphine sulfate, $3 \mathrm{mg}$ per $\mathrm{kg}$, and pentobarbital (Nembutal), $12 \mathrm{mg}$ per $\mathrm{kg}$, and studied without opening the chest. After insertion of an endotracheal tube, respiration was regulated with a Harvard respiratory pump, facilitating the maintenance of arterial oxygen saturation and $\mathrm{pH}$ in the normal range. Catheters were placed in the coronary sinus, pulmonary artery, aorta, and left ventricle for

* Submitted for publication March 2, 1965; accepted November 12, 1965.

Presented in part at the Annual Meeting of the American Heart Association, Los Angeles, October 1963, and abstracted in Circulation 1963, 28, 788.

Supported in part by grants from the Morris County Heart Association, the American Heart Association (61 F 82 EG), and the U. S. Public Health Service (H-5483, $\mathrm{H}-06376$, and 5TI HE 5510).

† This work was accomplished during the tenure of an Established Investigatorship of the American Heart Association, supported by the Essex County Heart Association.

Address requests for reprints to Dr. Timothy J. Regan, Dept. of Medicine, New Jersey College of Medicine, 24 Baldwin Ave., Jersey City, N. J. 07304. blood sampling and pressure determinations. Although initially the catheters were filled with dilute heparin, slow saline infusions or intermittent flushes were used during the experiment to maintain their patency. Since the level of arterial free fatty acids did not rise during the experiment, the earlier limited use of heparin did not appear to affect substrate concentrations.

During the evaluation of cardiac performance in the intact animal in experiments of many hours duration, a direct measurement of contractility utilizing the forcevelocity relationship is not feasible, but less direct methods may be employed to characterize myocardial function. Thus, contractility change has been deduced from the relation of stroke output to left ventricular end-diastolic pressure (LVEDP) $(6,7)$.

Sympathetic stimulation of isolated papillary muscle analyzed in terms of the force-velocity relationship has revealed an enhanced velocity of muscle shortening, representing a primary contractility increase (8). Sympathetic stimulation of the intact heart under conditions of controlled heart rate, before and after loading, has evoked an increase of stroke output as well as $\mathrm{dp} / \mathrm{dt}$ maximum of left ventricular pressure as manifestations of primary contractility increments (9).

A rise in LVEDP is normally associated with a corresponding stroke output increment (9), presumably a reflection of the rise in maximal isometric force without a velocity change that attends increased length of papillary muscle (8). The failure of stroke output to rise in this situation would appear to represent impaired muscle function $(6,9,10)$ particularly when the duration of systole is prolonged or unchanged (6). In this present study the ventricular ejection rate was analyzed in terms of ventricular systolic duration and the maximal rate of rise of left ventricular pressure $(\mathrm{dp} / \mathrm{dt})$ only in the $a b-$ sence of significant changes in heart rate and arterial pressure (11).

Ventricular and femoral arterial pressures were measured through $50-\mathrm{cm}$ Goodale-Lubin $8 \mathrm{~F}$ catheters connected directly to Statham P23D strain-gauge transducers. Photographic recordings were made from a multichannel Electronics for Medicine oscilloscope recorder at 5- to 10 -minute intervals. The frequency response of this recording system was linear from 0 to 30 cycles per second. The first derivative of the left ventricular pressure pulse $(\mathrm{dp} / \mathrm{dt})$ was continuously computed by an $\mathrm{R}-\mathrm{C}$ differentiating circuit and converted 
into millimeters of $\mathrm{Hg}$ per second (12). The amplitude of $\mathrm{dp} / \mathrm{dt}$ was a linear function of frequency to 70 cycles per second. Ventricular diastolic pressure was recorded at sufficient sensitivity so that $1 \mathrm{~mm} \mathrm{Hg}$ equaled $5 \mathrm{~mm}$ of paper. All measurements were made at the end-expiration phase of the respiratory cycle. Cardiac output was measured by dye dilution, and the control values were not obtained until $2 \frac{1}{2}$ to 3 hours after anesthetic induction, when further decline of cardiac output after pentobarbital is no longer observed (13).

Simultaneous blood samples from the arterial and coronary sinus were taken for determination of arteriovenous differences of substrates. The blood was placed in chilled tubes containing EDTA, and after separation in a refrigerated centrifuge, the plasma was stored at $-15^{\circ} \mathrm{C}$ before analysis. Samples were drawn at 25,15 , and $5 \mathrm{~min}$ utes before alcohol infusion was begun, and at 15- to 30 minute intervals for 3 to 5 hours after the start of the infusion. Substrate determinations were done in duplicate and included glucose (14), lactate (15), pyruvate (16), free fatty acid (17), triglyceride (18), and phospholipid (19). The triglyceride method was modified, using a Fluorosil column in place of silicic acid to more effectively exclude phospholipid from the chloroform eluate (20), which was verified by thin layer chromatography. Left ventricular tissue taken for lipid analysis was quickly frozen with liquid nitrogen, after careful trimming to remove the pericoronary adipose tissue from the epicardium. The tissue was homogenized in phosphate buffer and the lipid extracted as for plasma. Plasma samples without significant hemolysis were also analyzed for glutamic oxaloacetic transaminase (21) and phosphate ion (22). Plasma potassium was analyzed on a Beckman B spectrophotometer with a flame attachment. Duplicate determinations for blood oxygen and carbon dioxide were performed by the method of Van Slyke and Neill (23), and arterial pH was determined on a Beckman meter at $37^{\circ} \mathrm{C}$. Ethanol samples were analyzed by the microdiffusion method of Conway (24). Donor animals were used for $35-\mathrm{ml}$ blood replacements after each arterial-coronary sinus sampling, which procedure had no apparent effect on substrate extraction in the control observations before ethanol administration.

To assess the changes in left ventricular blood flow, we made sequential flow measurements, injecting ${ }^{85} \mathrm{kryp}-$ ton (25) into the left coronary artery via a Sones catheter. This catheter was placed proximal to the atrial artery by angiogram and produced no evidence of ischemia in terms of ST-T changes on epicardial electrocardiograms obtained from the coronary artery and coronary sinus catheter. Further, separate experiments using electromagnetic flow probes on the coronary artery showed no change in phasic coronary flow with the catheter in this position. Control animals have shown no significant variation in coronary flow over a period of several hours provided heart rate and arterial pressure are relatively unchanged.

In the interpretation of arteriovenous differences the requirements for relatively constant coronary blood flow and arterial substrate concentrations (26) were met after the first hour of alcohol infusion. The steady state flow condition was rapidly established due to the 30 -second duration of the longest transit time in canine heart (27). The rise in arterial concentration of glucose and lactate had leveled off between 1 and 11 hours (Table I). Since the equilibration of the changed arterial concentration of these substrates with tissue is accomplished within 10 to 15 minutes (28), the altered arterial-coronary sinus (A-CS) differences subsequent to this time appear to be valid. Four animals were excluded from the study due to the lack of a period of constancy, with variations in arterial substrate concentrations or of coronary flow greater than the error of analysis, which was $10 \%$ in the case of lipid and blood flow determinations and $5 \%$ for carbohydrate substrates.

Ethanol (U.S.P.) was dissolved in water to make a $15 \%$ solution and administered through a femoral venous catheter for approximately 2 hours at a rate of $0.1 \mathrm{mg}$ per $\mathrm{kg}$ per minute after an initial priming dose of $0.2 \mathrm{ml}$ per $\mathrm{kg}$ per minute for 12 minutes. Visible hemolysis usually did not result from this infusion. This dosage, averaging a total of $36 \mathrm{~g}$, was sufficient to produce in a separate group of seven animals a nearly threefold increase of hepatic triglyceride, compared to a group of fasted animals, within 18 hours after ethanol had been administered. Hence, the acute cardiac effects described below were elicited at a dosage level associated with the wellknown lipid accumulation in the liver (2). To assess the possible contribution of sustained anesthesia to the hemodynamic changes elicited after ethanol, we gave a separate group of six animals an isovolumic amount of saline and observed them for a similar period. Whereas the ethanol group required no anesthetic supplements to control respiratory movements, that receiving saline received $50 \mathrm{mg}$ of pentobarbital at about 90 -minute intervals. To evaluate a possible caloric effect on myocardial lipid metabolism, we infused glucose in isocaloric amounts (26 mg per $\mathrm{kg}$ per minute) for 2 hours in five control animals. Statistical variations are expressed as standard errors (29).

\section{Results}

The arterial concentration of ethanol was $110 \pm$ $13 \mathrm{mg}$ per $100 \mathrm{ml}$ after 30 minutes of infusion and reached a peak of $201 \pm 11 \mathrm{mg}$ per $100 \mathrm{ml}$ at the end of the 2 hours. Ethanol produced evidence of depressed left ventricular contractility by $15 \mathrm{~min}$ utes, unaccompanied by significant changes in heart rate or systemic arterial pressure (Figure 1). LVEDP rose from $5 \mathrm{~mm} \mathrm{Hg}$ to a maximum of $9.8 \mathrm{~mm} \mathrm{Hg}$ by 30 minutes $(\mathrm{p}<0.01)$ and remained elevated through the 5 hours of observation. Instead of the expected increase in stroke output with the filling pressure rise (7), this parameter was persistently diminished $(\mathrm{p}<$ 0.001 ) with only partial recovery by 5 hours. The impaired contractility was also reflected in a re- 

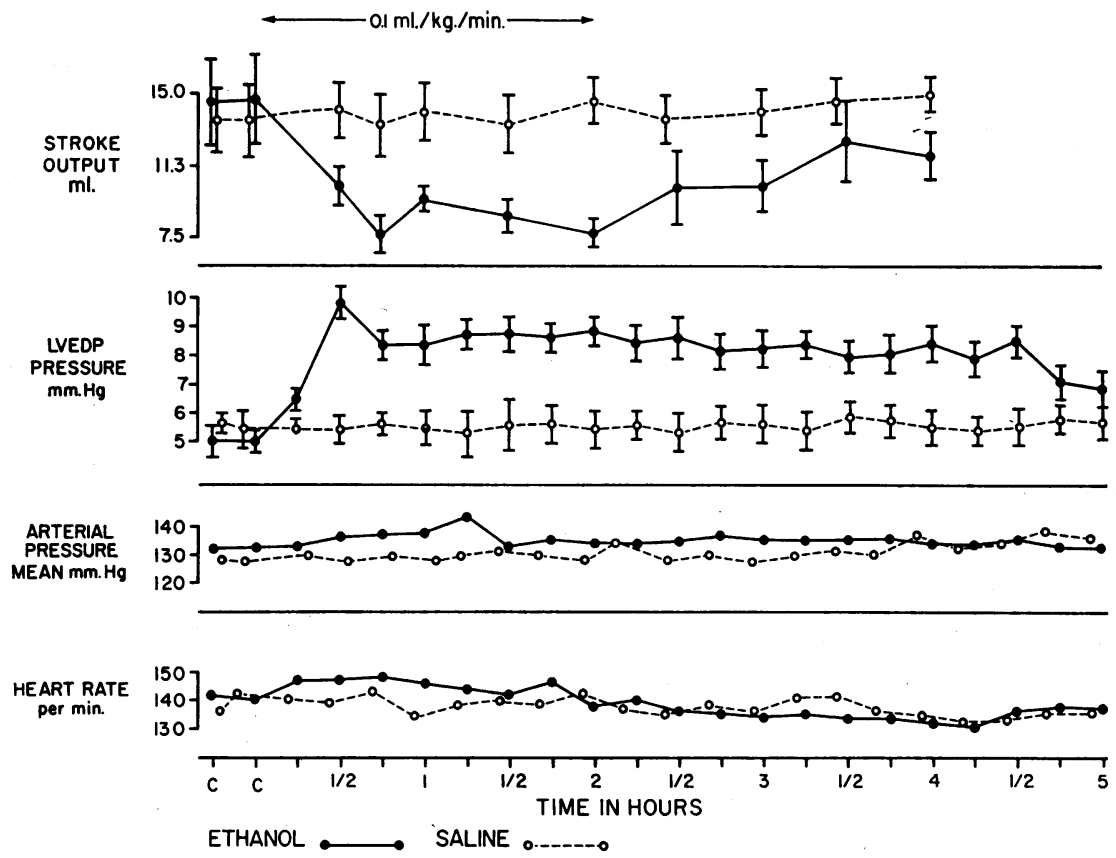

Fig. 1. Hemodynamic Response to ethanol (eight dogs) and SAline (SiX dogs). In contrast to the saline response, which produced no significant changes in left ventricular parameters, a rise in left ventricular end-diastolic pressure (LVEDP) after ethanol was associated with a decline in stroke output followed by partial recovery. No significant change in heart rate or arterial pressure occurred in either group. Vertical lines represent standard errors.

duced left ventricular $\mathrm{dp} / \mathrm{dt}$ maximum that paralleled the time course of stroke output. From a mean control value of $2,750 \pm 48 \mathrm{~mm} \mathrm{Hg}$ per second, $\mathrm{dp} / \mathrm{dt}$ progressively declined to a value of $2,075 \pm 56 \mathrm{~mm} \mathrm{Hg}$ per second by 45 minutes $(\mathrm{p}<$ $0.001)$, when the stroke output decline was greatest. Since the duration of ventricular systole was not significantly altered from a control of $153 \pm$ 6 milliseconds, the stroke output per second of ventricular systole was clearly diminished after ethanol.

Saline infusion, begun $2 \frac{1}{2}$ to 3 hours after anesthetic induction, was accompanied by no significant change in LVEDP or stroke output (Figure 1) or in $\mathrm{dp} / \mathrm{dt}$ and the duration of ventricular systole during the 5 hours of observation. In neither group was there a significant change in heart rate or arterial pressure.

Evidence for a direct cardiac effect of ethanol independent of central nervous system effects was obtained during the infusion of $78 \mathrm{mg}$ of ethanol per minute into a left coronary arterial catheter in seven animals. Whereas saline infusion $(0.1 \mathrm{ml}$ per minute) produced no effects on LVEDP or $\mathrm{dp} / \mathrm{dt}$, the same volume of ethanol produced a rise of $2.1 \pm 0.2 \mathrm{~mm} \mathrm{Hg}$ in LVEDP with an associated decrease in $\mathrm{dp} / \mathrm{dt}$ maximum of $625 \pm 38 \mathrm{~mm}$ $\mathrm{Hg}$ per second. This effect was uniformly present within 10 minutes when systemic blood ethanol concentrations were not significantly elevated and is qualitatively similar to that found during systemic ethanol infusion.

In five of the eight animals receiving ethanol, ventricular ectopic beats with a frequency of 2 to 5 per minute were seen from 30 minutes to $2 \frac{1}{2}$ hours. These were not present in the control animals receiving saline.

The earliest significant changes in coronary blood flow after ethanol administration (Figure 2) occurred after the onset of the contractility decline (Figure 1). Coronary flow did not decline significantly until the 30 -minute observation, when a decrease of $15 \%$ was found $(p<0.05)$. After 60 minutes, flow was not significantly different from control, and there was no indication of reactive hyperemia. The extraction of oxygen by the left ventricle was reduced (Figure 2 ), and no evidence 
of excess lactate production was found (Table I). Since acute reduction of coronary flow by arterial ligation results in increased oxygen extraction, lactate production, and reactive hyperemia (30), the coronary flow reduction would appear to represent a secondary response to the decline in ventricular activity during ethanol infusion.

However, evidence for some degree of ventricular tissue injury was observed after ethanol (Figure 2). Significant elevations in coronary sinus concentrations of potassium $(\mathrm{p}<0.01)$ and phosphate $(p<0.001)$ occurred from $1 \frac{1}{2}$ to $2 \frac{1}{2}$ hours before there was a significant rise in arterial concentrations. This was followed by the appearance of the transaminase enzyme in the coronary venous effluent through 4 hours $(p<0.01)$. In the later time interval the negative arterial-coronary sinus differences were probably underestimated in view of the rising arterial concentrations. Control animals infused with glucose exhibited no transaminase release from the myocardium.

The changes in carbohydrate metabolism of the left ventricle after ethanol are indicated in Table I. A significant rise in respiratory quotient (RQ) occurred by $1 \frac{1}{2}$ hours, at least partially related to the rise in extraction of glucose and lactate by the myocardium. The $R Q$ calculated from substrate extraction in the control period was in close agreement with the experimental value. However, the $\mathrm{RQ}$ of 0.85 estimated from the extraction data, including a presumed value for acetate (31), was somewhat lower than the experimentally derived
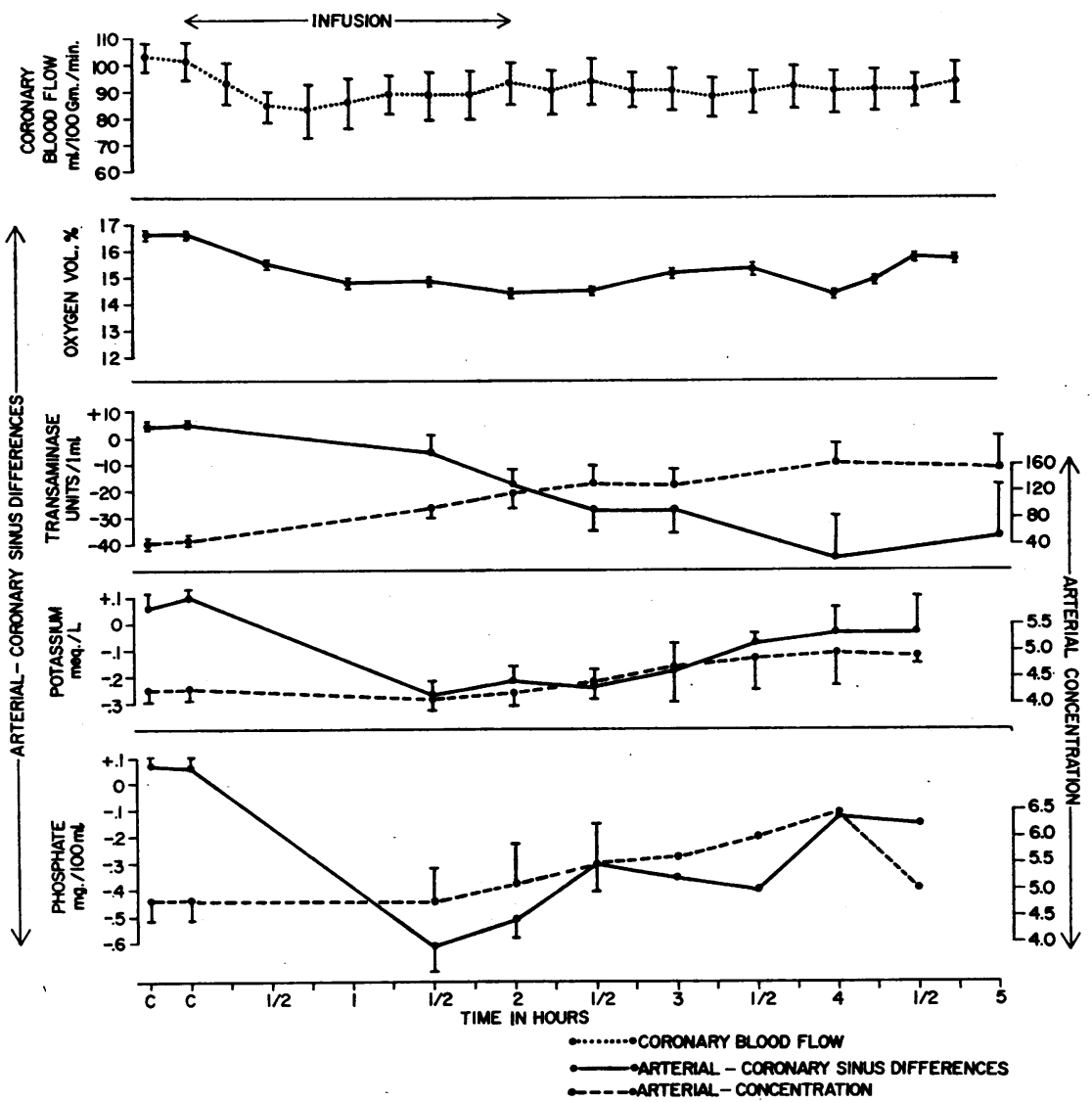

Fig. 2. Evidence for myocardial NeCROSIS AFTer ETHANOL. The small but significant decease of coronary blood flow from 30 to 60 minutes was not attended by an increase in oxygen extraction in the eight animals studied. A significant rise in coronary sinus concentrations of potassium and phosphate ions was found by 90 minutes before a significant change in arterial concentrations occurred. The period of level arterial concentrations of the transaminase enzyme after $2 \frac{1}{2}$ hours was associated with substantial coronary sinus increments. The standard errors are indicated only above or below the mean to minimize line overlap. 
TABLE I

Left ventricular carbohydrate metabolism during ethanol infusion in eight dogs

\begin{tabular}{|c|c|c|c|c|c|c|c|c|c|c|c|c|}
\hline $\begin{array}{l}\text { Time in } \\
\text { hours: }\end{array}$ & C & C & C* & 1.25 & 1.5 & 2 & 2.5 & 3 & 3.5 & 4 & 4.5 & 5 \\
\hline \multirow{2}{*}{\multicolumn{2}{|c|}{$\begin{array}{c}\text { Respiratory } \\
\text { quotient }\end{array}$}} & 0.73 & 0.72 & & $0.92 \dagger$ & & 0.73 & & & 0.70 & & \\
\hline & & \pm 0.03 & 0.02 & & 0.02 & & 0.03 & & & 0.01 & & \\
\hline \multicolumn{13}{|c|}{ Glucose, $m$ moles $/ L$} \\
\hline \multirow[t]{2}{*}{ Arterial } & 4.83 & 4.84 & 4.84 & 5.71 & 5.78 & 5.52 & 4.69 & 4.65 & 4.5 & 4.6 & 4.65 & 4.44 \\
\hline & \pm 0.38 & 0.40 & 0.39 & 1.10 & 1.09 & 1.01 & 0.39 & 0.49 & 0.35 & 0.35 & 0.36 & 0.35 \\
\hline \multirow[t]{2}{*}{ A-CS $¥$} & 0.48 & 0.48 & . 0.46 & $1.11 \dagger$ & $0.81 t$ & 0.52 & 0.37 & 0.29 & 0.31 & 0.30 & 0.31 & 0.34 \\
\hline & \pm 0.12 & 0.13 & 0.12 & 0.14 & 0.12 & 0.08 & 0.09 & 0.07 & 0.09 & 0.09 & 0.08 & 0.10 \\
\hline \multicolumn{13}{|c|}{ Pyruvate, mmoles $/ L$} \\
\hline \multirow[t]{2}{*}{ Arterial } & 0.32 & 0.31 & 0.32 & $0.26 \&$ & 0.278 & 0.278 & $0.28 \S$ & 0.29 & 0.29 & 0.30 & 0.33 & 0.33 \\
\hline & \pm 0.05 & 0.04 & 0.06 & 0.06 & 0.06 & 0.07 & 0.07 & 0.09 & 0.07 & 0.06 & 0.07 & 0.07 \\
\hline \multirow[t]{2}{*}{ A-CS } & 0.10 & 0.09 & 0.10 & 0.048 & 0.06 & 0.06 & 0.06 & 0.05 & 0.06 & 0.08 & 0.09 & 0.09 \\
\hline & \pm 0.02 & 0.01 & 0.02 & 0.01 & 0.01 & 0.02 & 0.02 & 0.01 & 0.01 & 0.01 & 0.02 & 0.02 \\
\hline \multicolumn{13}{|c|}{ Lactate, mmoles $/ L$} \\
\hline \multirow[t]{2}{*}{ Arterial } & 2.63 & 2.63 & 2.61 & 4.018 & $4.04 \dagger$ & 4.14 & 4.37 & 4.17 & 4.13 & 4.13 & 4.13 & 4.46 \\
\hline & \pm 0.46 & 0.47 & 0.49 & 0.84 & 0.79 & 0.87 & 1.23 & 0.88 & 0.87 & 0.85 & 0.84 & 1.09 \\
\hline \multirow[t]{2}{*}{ A-CS } & 0.51 & 0.53 & 0.47 & $1.28 \dagger$ & $1.03 t$ & 0.888 & 0.63 & $0.77 \S$ & $0.71 \S$ & 0.62 & 0.55 & 0.49 \\
\hline & \pm 0.07 & 0.08 & 0.10 & 0.09 & 0.11 & 0.13 & 0.21 & 0.12 & 0.11 & 0.09 & 0.06 & 0.08 \\
\hline \multicolumn{13}{|c|}{ Excess lactate, mmoles $/ L$} \\
\hline & -0.25 & -0.19 & +0.03 & $-0.6 \S$ & -0.43 & -.49 & -0.578 & -0.47 & -0.42 & -0.26 & +0.17 & -0.145 \\
\hline & \pm 0.08 & 0.127 & 0.13 & 0.08 & 0.06 & 0.13 & 0.11 & 0.08 & 0.04 & 0.09 & 0.11 & 0.11 \\
\hline
\end{tabular}

* Control values; data expressed as means \pm standard errors.

$+\mathrm{p} \leq .02$.

$\ddagger \mathrm{A}-\mathrm{CS}=$ arterial-coronary sinus differences.

$\$ \mathrm{p}<.05$.

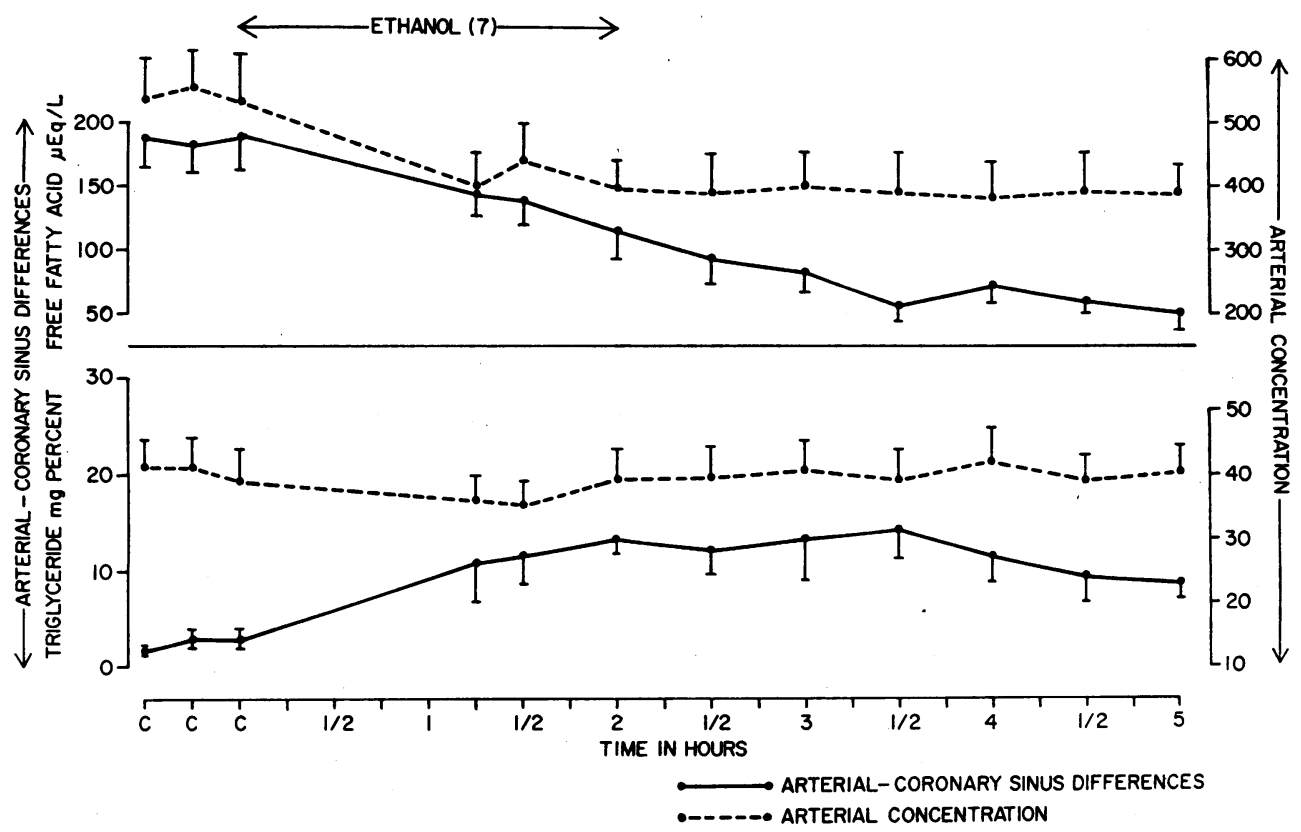

Fig. 3. Lipid UPtake IN LEFT ventricle. Arterial free fatty acid levels declined during the initial hour of ethanol infusion. With constant levels thereafter, the myocardial extraction was substantially reduced. In the presence of a relatively unchanged arterial concentration the extraction of triglyceride was significantly increased from 90 minutes until termination of the experiment. 
value. This may indicate that the oxidation of fatty acids extracted at this time as free fatty acid or triglyceride was under a certain degree of inhibition.

The rise in arterial level of both glucose and lactate had leveled off by $1 \frac{1}{4}$ hours, but only in the case of glucose was the extraction increment proportionately greater than the arterial concentration rise. The decline in arterial pyruvate concentrations was probably related to a reduced hepatic output, since hepatic venous concentrations of this substrate have been noted to decline after ethanol (32). The failure to find lactate production by the heart is in accord with the apparent absence of alcohol dehydrogenase in this tissue for the metabolic degradation of ethanol.

The myocardial $R Q$ reverted to control levels by $2 \frac{1}{2}$ hours. This reversion to a predominant dependence upon lipid for oxidative needs was not met, as in the control period, by plasma free fatty acid, since the uptake of this substrate was significantly reduced $(<0.01)$ throughout the rest of the experiment (Figure 3 ). The modest reduction of arterial concentration accomplished in the first hour and described in another study (33) was proportionately less than the change in extraction. Simultaneous with this phenomenon, triglyceride extraction was substantially enhanced
TABLE II

Left ventricular lipids

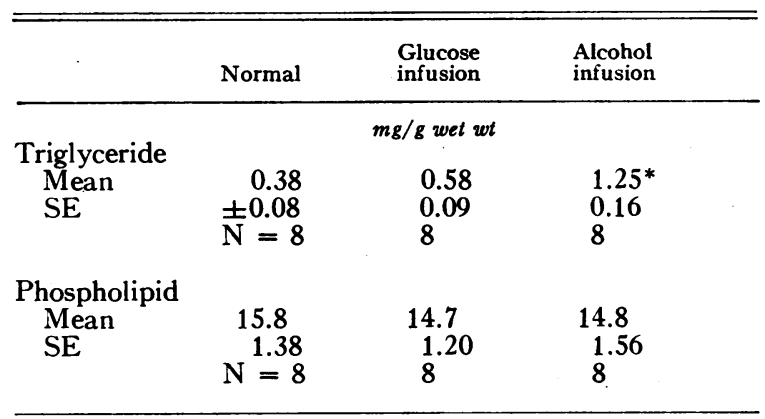

${ }^{*}$ Significant at $\mathrm{p}<0.01$.

$(\mathrm{p}<0.01)$ and was presumably the predominant lipid serving as substrate for oxidation. This altered pattern of lipid extraction persisted through 5 hours of observation. Further, the left ventricular concentration of triglyceride was significantly increased above that of fasting and glucose-fed controls after 5 hours (Table II), in the presence of a normal tissue water content of $79 \pm 1.2 \%$ (compared to $78 \pm 1.4 \%$ in controls). Tissue phospholipid concentration was not altered.

Despite a slight elevation of arterial triglyceride and a small decrease of arterial free fatty acid, there was no significant change in the myocardial extraction of these substrates during glucose infu-

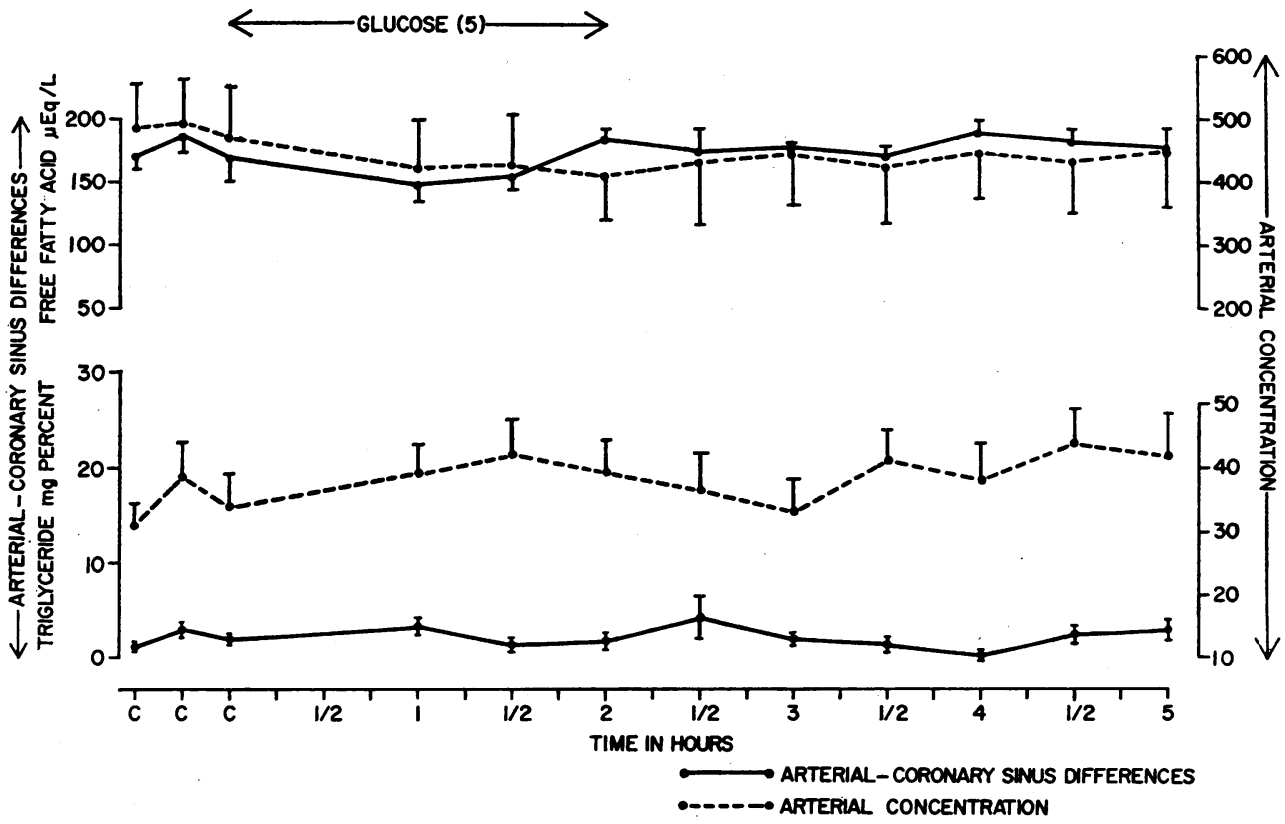

Fig. 4. Lipid UPTAKe IN LEFT ventricle. During glucose infusion there was no significant change in arterial concentrations or myocardial extraction of lipid substrates. 
TABLE III

Plasma volume change during ethanol infusion $(n=8)$

\begin{tabular}{|c|c|c|c|c|c|c|c|c|}
\hline Time in hours: & $\mathrm{C}$ & C & 0.25 & 0.5 & 0.8 & 1.25 & 1.5 & 2.0 \\
\hline $\begin{array}{l}\text { Serum osmolality, } \\
\quad m O s m / L \\
\mathrm{SE}\end{array}$ & $\begin{array}{l}289 \\
\pm 3\end{array}$ & $\begin{array}{r}290 \\
2\end{array}$ & $\begin{array}{r}308 \\
4\end{array}$ & $\begin{array}{r}322 \\
3\end{array}$ & $\begin{array}{r}334 \\
2\end{array}$ & $\begin{array}{r}341 \\
4\end{array}$ & $\begin{array}{r}350 \\
5\end{array}$ & $\begin{array}{r}348 \\
3\end{array}$ \\
\hline $\begin{array}{l}\text { Plasma volume, } \\
m l \\
\mathrm{SE}\end{array}$ & $\begin{array}{r}720 \\
\pm 12\end{array}$ & $\begin{array}{r}714 \\
9\end{array}$ & & $\begin{array}{r}870 \\
8\end{array}$ & $\begin{array}{r}775 \\
11\end{array}$ & $\begin{array}{r}766 \\
7\end{array}$ & $\begin{array}{r}782 \\
13\end{array}$ & $\begin{array}{r}764 \\
10\end{array}$ \\
\hline
\end{tabular}

sion (Figure 4). Hence, the effects of ethanol on left ventricular function and metabolism do not appear related to its caloric effects.

\section{Discussion}

A depressant effect of ethanol on the ventricular contractility of various species has been described at high concentrations of blood alcohol, 400 to $1,000 \mathrm{mg}$ per $100 \mathrm{ml}$ (34-36), and has been verified in an isolated rat atrial preparation at concentrations as low as $100 \mathrm{mg}$ per $100 \mathrm{ml}$ (37), which approximates the dosage and myocardial response of the present study. The reduction of stroke output in the presence of a ventricular filling pressure rise of $5 \mathrm{~mm} \mathrm{Hg}$ in the intact animal represents a substantial decline of left ventricular function. An acute change in end-diastolic compliance, a subject of dispute in cardiac physiology (38), might account for the filling pressure alteration. However, a normally responding ventricle, given an unchanged ventricular ejection period, would be expected to effect a stroke output increment $(6,9,10)$.

Although the change of atrial function in the rat study was reversible, the exposure to ethanol was maintained for only 30 minutes (37). The fact that left ventricular contractility remained depressed through the 5 hours of observation in the intact dog could be related to the persistence of ethanol in the blood or to the cardiac tissue injury evident during the course of infusion. The partial return of ventricular function in the later stages of the experiment is compatible with either interpretation.

If the necrosis of left ventricular tissue is not related to inadequate coronary flow as suggested, then a direct effect on cardiac muscle is probable in view of the decline of function during coronary arterial infusion and in the isolated heart (37).
A deleterious effect of ethanol on membrane function of skeletal muscle has been postulated (39), but only minimal changes in action potential were observed at the lowest concentration of alcohol used. This concentration was more than twice that achieved in the present study at the time of maximal ventricular function decline. A mechanism involving an osmolar gradient, which is known to depress cardiac contractility (40), has been postulated as a possible mode of action (41). This is based on finding a substantial rise of serum osmolality by the freezing point depression method and a net plasma volume increase of $18 \%$ ( ${ }^{131}$ I-labeled albumin) after the onset of ethanol infusion (Table III). That a real increment in the osmotic activity of plasma was present is supported by the fact that the maximal expansion of plasma volume was present by 30 minutes, with a subsequent decline to a level $5 \%$ above control when the 2-hour infusion was terminated. The transient nature of this phenomenon is consistent with a delayed equilibration of extravascular osmolality with the osmolar activity of the vascular compartment.

Since the vascular effects of hyperosmolar solutions have been reduced by sympathectomy (42), the evidence advanced for sympathetic stimulation after ethanol (3) may be related to its osmotic effect. Unless the cardiac manifestations of a catecholamine influence are inhibited by ethanol, however, a relatively small sympathetic stimulus must be present in view of the lack of expected increments in heart rate, contractility, and coronary blood flow (43). The diphasic response of the myocardial $R Q$ and the increment in triglyceride uptake, with eventual accumulation in left ventricular tissue, do resemble the metabolic responses to catecholamine infusion $(4,5)$.

Conversely, a pharmacologic effect of ethanol that depletes myocardial catecholamine stores or 
inhibits beta receptor activity may be suggested as a mechanism by which ventricular function is diminished. However, the rapid onset of the ethanol effect would make depletion of norepinephrine stores unlikely. More importantly, neither this mechanism nor pharmacologic inhibition of beta receptors is known to produce a substantial stroke output reduction in the presence of elevated ventricular filling pressure $(44,45)$.

The accumulation of triglyceride in the left ventricle has been found in various pathological situations $(5,46-48)$, but a direct role for this metabolic aberration in modifying ventricular function has yet to be established, Particularly pertinent to this study is the fact that patients whose deaths were attributed to alcoholic cardiomyopathy have been found to have triglyceride deposited diffusely through the left ventricle as a prominent feature of histochemical examination (49).

One possible mechanism for the myocardial lipid accumulation observed in this study might involve inhibition of oxidation of the free fatty acid entering the cardiac cell (46), resulting in a tissue triglyceride increment through esterification with glycerol phosphate. This would seem unlikely in view of the substantial reduction of free fatty acid uptake in the presence of a respiratory quotient, after 90 minutes of ethanol infusion, which indicated predominant dependence upon lipid for oxidative needs.

The mechanism for the reduced extraction of free fatty acid may be related to the increased arterial concentrations of acetate produced after ethanol (31), when the myocardial utilization of this substrate, assuming practically complete oxidation (50), may be enhanced fivefold (31). The competitive inhibition of free fatty acid uptake seen with acetoacetate (51) may also obtain for acetate. A similar competitive inhibition may be ascribed to lactate and glucose, which are extracted in increased amounts early in the course of ethanol infusion. However, the persistence of diminished fatty acid extraction, when the extraction of these latter substrates and the respiratory quotient have reverted to near control levels, suggests another mechanism, possibly related to the enhanced triglyceride uptake.

The extraction of triglyceride by the myocardium in the fasting state is controversial (52,
53). Our own data and those of an earlier study using direct measurement of triglyceride (53) have failed to show significant uptake. However, a small positive arteriovenous difference of this substrate, undetected by present methods, could provide a significant amount of fatty acid in view of the fatty acid to glycerol molar ratio of three.

The enhanced uptake of triglyceride after ethanol may itself account in large measure for the tissue increment of triglyceride. This would imply a limit to the oxidative capacity of the myocardium when substantial uptake of triglyceride occurs. Whether this is absolute or conditioned by the increased uptake of carbohydrate substrate remains to be determined. It is noteworthy that the triglyceride changes were not dependent on an elevated arterial concentration of this lipid, a frequent consequence after ethanol infusion (54). The lack of rise of arterial triglyceride may be related to the influence of ethanol on the lipoprotein system required for triglyceride transport out of the liver (55) or may represent an effect of anesthesia on hepatic blood flow or metabolism.

In these animal studies the evidence of cardiac muscle damage suggests a direct effect of ethanol, which may be related to the decline in contractility. Selective release of ions and protein has been described early in the course of injury in noncardiac tissue (56). Although negative arterial-coronary sinus differences of potassium and phosphate ions to the degree observed here may be observed after strophanthidin $(57,58)$, the ion egress is limited to a period of 5 to 10 minutes. In the present state of our knowledge a sustained release of ions for the period of approximately 2 hours seen after ethanol administration does not appear to occur in a normally functioning ventricle. The pattern of ion and enzyme release from the myocardium after ethanol is similar to that occurring during ischemic necrosis $(59,60)$, but appears to be shorter in duration, presumably a reflection of a tissue injury that is reversible at this dosage level.

The accumulative effects of ethanol on the cardiovascular system of man have been largely attributed to associated dietary deficiency. Specifically, a deficiency of thiamine has been related to the high output state, beriberi (61). It is not clear how much of this complex phenomenon occurring in patients with hepatic cirrhosis is related to anemia or to the expanded extracellular 
volume due to sodium retention, rather than to a dietary deficiency. Further, the specific role of thiamine lack in producing cardiac disease is unclear, since chronic thiamine deficiency in the dog has produced no clear evidence of an impaired myocardium (62). A more detailed assessment of cardiac function in this situation is required to define more adequately the consequences of this vitamin deficiency and its interrelation with ethanol usage.

Studies during ethanol ingestion in man indicate acute effects on cardiac function in the alcoholic human subject (63) similar to those of the animal experiments. Whether the accumulative effect of repeated exposure to ethyl alcohol in substantial quantities, particularly when rapidly ingested, may constitute a mechanism for the production of cardiac disease in the chronic alcoholic remains to be established. Since an acute skeletal muscle myopathy has been described in man (64), with symptoms appearing after a period of high alcohol intake, muscle tissue may be considered, together with brain and liver, as susceptible to functional impairment when exposed to from moderate to substantial amounts of ethanol.

\section{Summary}

The hemodynamic and metabolic effects of $15 \%$ ethanol, $0.1 \mathrm{ml}$ per $\mathrm{kg}$ per minute, infused systemically for 2 hours, have been studied in the intact anesthetized dog. Diminished left ventricular function, manifested as a decline of stroke output and rise of end-diastolic pressure, was observed as early as 15 minutes, was well established by 30 minutes at blood alcohol concentrations of $110 \pm$ $13 \mathrm{mg}$ per $100 \mathrm{ml}$, and persisted through 5 hours without significant heart rate or arterial pressure changes. A small transient decline in coronary blood flow was not considered a primary factor in the decline of left ventricular function. Evidence of cardiac tissue injury was observed after $90 \mathrm{~min}$ utes, with significant elevations of coronary sinus potassium and phosphate ion concentrations as well as of the transaminase enzyme. Substantial recovery toward control was present by the end of 5 hours of observation.

The myocardial metabolic response to ethanol included an initial shift in the respiratory quotient to that characteristic of predominant carbohydrate oxidation. During this period left ventricular glu- cose and lactate extractions were enhanced. Subsequently, the respiratory quotient declined to levels consistent with predominant lipid utilization. Although free fatty acid uptake was significantly diminished, plasma triglyceride became the predominant myocardial substrate through the remaining observation period. Left ventricular triglyceride concentration was found to be enhanced threefold above fasted controls, so that this unique change in lipid transport appeared to make a major contribution to the accumulation of lipid in the myocardium.

Control experiments, employing saline or glucose infusions, revealed neither depression of ventricular function nor myocardial release of the transaminase enzyme, and no significant triglyceride uptake or tissue accumulation occurred.

\section{Acknowledgments}

We wish to express our appreciation for the technical assistance of Mrs. Carla O'Brien, Mrs. Elizabeth Jenkins, Mrs. Regina Braun, and Miss Barbara Failla, and for the secretarial assistance of Mrs. Phyllis Moschos.

\section{References}

1. Goodman, L. S., and A. Gilman. The Pharmacological Basis of Therapeutics, 2nd ed. New York, Macmillan, 1955, p. 99.

2. Maickel, R. P., and B. B. Brodie. Interaction of drugs with pituitary-adrenocortical system in the production of the fatty liver. Ann. N. Y. Acad. Sci. 1963, 104, 1059.

3. Siegel, J. H. The effect of enteric ethanol on arterial and portal venous catechol amines (abstract). Clin. Res. 1964, 12, 213.

4. Regan, T. J., L. Troum, P. H. Lehan, and H. K. Hellems. Myocardial metabolism during epinephrineinduced necrosis (abstract). J. clin. Invest. 1962, 42, 1393.

5. Maling, H. M., B. Highman, and E. C. Thompson. Some similar effects after large doses of catecholamines and myocardial infarction in dogs. Amer. J. Cardiol. 1960, 5, 628.

6. Sonnenblick, E. H., and S. E. Downing. Afterload as a primary determinant of ventricular performance. Amer. J. Physiol. 1963, 204, 604.

7. Downing, S. E., and E. H. Sonnenblick. Force and velocity parameters in the intact heart (abstract). Circulation 1963, 28, 712.

8. Sonnenblick, E. H. Implications of muscle mechanics in the heart. Fed. Proc. 1962, 21, 975.

9. Sarnoff, S. J., and J. H. Mitchell. The regulation of the performance of the heart. Amer. J. Med. 1961, 30, 747. 
10. Downing, S. E. Effects of angiotensin II and norepinephrine on ventricular performance during oligemic shock. Yale J. Biol. Med. 1964, 36, 407.

11. Wallace, A. G., N. S. Skinner, Jr., and J. H. Mitchell. Hemodynamic determinants of the maximal rate of rise of left ventricular pressure. Amer. J. Physiol. 1963, 205, 30.

12. Reeves, T. J., L. L. Hefner, W. B. Jones, C. Goghlan, G. Prieto, and J. Carroll. The hemodynamic determinants of the rate of change in pressure in the left ventricle during isometric contraction. Amer. Heart J. 1960, 60, 745.

13. Nash, C. B., F. Davis, and R. A. Woodbury. Cardiovascular effects of anesthetic doses of pentobarbital sodium. Amer. J. Physiol. 1956, 185, 107.

14. Nelson, N. A photometric adaptation of the Somogyi method for the determination of glucose. J. biol. Chem. 1944, 153, 375.

15. Barker, S. B., and W. H. Summerson. The colorimetric determination of lactic acid in biological material. J. biol. Chem. 1941, 138, 535.

16. Friedemann, T. E., and G. E. Haugen. Pyruvic acid. II. The determination of keto acids in blood and urine. J. biol. Chem. 1943, 147, 415.

17. Gordon, R. S., Jr. Unesterified fatty acid in human blood plasma. II. The transport function of unesterified fatty acid. J. clin. Invest. 1957, 36, 810.

18. Carlson, L. A., and L. B. Wadström. Determination of glycerides in blood serum. Clin. chim. Acta 1959, 4, 197.

19. Bartlett, G. R. Phosphorus assay in column chromatography. J. biol. Chem. 1959, 234, 466.

20. Carroll, K. K. Separation of lipid classes by chromatography on Florisil. J. Lipid Res. 1961, 2, 135.

21. Karmen, A., F. Wroblewski, and J. S. LaDue. Transaminase activity in human blood. J. clin. Invest. 1955, 34, 126.

22. Fiske, C. H., and Y. Subbarow. The colorimetric determination of phosphorus. J. biol. Chem. 1925, 66, 375.

23. Van Slyke, D. D., and J. M. Neill. The determination of gases in blood and other solutions by vacuum extraction and manometric measurement. J. biol. Chem. 1924, 61, 523.

24. Conway, E. J. Microdiffusion Analysis and Volumetric Error. New York, Macmillan, 1956, p. 248.

25. Herd, J. A., M. Hollenberg, G. D. Thorburn, H. H. Kopald, and A. C. Barger. Myocardial blood flow determined with krypton ${ }^{85}$ in unanesthetized dogs. Amer. J. Physiol. 1962, 203, 122.

26. Zierler, K. L. Theory of the use of arteriovenous concentration differences for measuring metabolism in steady and non-steady states. J. clin. Invest. 1961, 40, 2111.

27. Friesinger, G. C., J. Schaefer, R. A. Gaertner, and R. S. Ross. Coronary sinus drainage and measurement of left coronary artery flow in the dog. Amer. J. Physiol. 1964, 206, 57.
28. Danforth, W. H., J. J. McKinsey, and J. T. Stewart. Transport and phosphorylation of glucose by the dog heart. J. Physiol. (Lond.) 1962, 162, 367.

29. Batson, H. C. An Introduction to Statistics in the Medical Sciences. Minneapolis, Burgess, 1961, pp. 14-18.

30. Coffman, J. D., and D. E. Gregg. Oxygen metabolism and oxygen debt repayment after myocardial ischemia. Amer. J. Physiol. 1961, 201, 881.

31. Lindeneg, O., K. Mellemgaard, J. Fabricius, and F. Lundquist. Myocardial utilization of acetate, lactate and free fatty acids after ingestion of ethanol. Clin. Sci. 1964, 27, 427.

32. Cherrick, G., and C. M. Leevy. Personal communication.

34. Loomis, T. A. Effect of alcohol on myocardial and respiratory function. The influence of modified respiratory function on the cardiac toxicity of alcohol. Quart. J. Stud. Alcohol 1952, 13, 561.

35. Haggard, H. W., L. A. Greenberg, L. H. Cohen, and N. Rakieten. Studies on the absorption, distribution and elimination of alcohol. IX. The concentration of alcohol in the blood causing primary cardiac failure. J. Pharmacol. exp. Ther. 1941, $71,358$.

36. Wakim, K. G. The effects of ethyl alcohol on the isolated heart. Fed. Proc. 1946, 5, 109.

37. Gimeno, A. L., M. F. Gimeno, and J. L. Webb. Effects of ethanol on cellular membrane potentials and contractility of isolated rat atrium. Amer. J. Physiol. 1962, 203, 194.

38. Sonnenblick, E. H., J. H. Siegel, and S. J. Sarnoff. Ventricular distensibility and pressure-volume curve during sympathetic stimulation. Amer. J. Physiol. 1963, 204, 1.

39. Knutsson, E. Effects of ethanol on the membrane potential and membrane resistance of frog muscle fibers. Acta physiol. scand. 1961, 52, 242.

40. Koch-Weser, J. Influence of osmolarity of perfusate on contractility of mammalian myocardium. Amer. J. Physiol. 1963, 204, 957.

41. Regan, T. J., A. B. Weisse, H. A. Oldewurtel, and H. K. Hellems. The hyperosmotic effects of ethanol and sucrose on the left ventricle. J. clin. Invest. 1964, 43, 1289.

42. Lasser, R. P., M. R. Schoenfeld, D. F. Allen, and C. K. Friedberg. Reflex circulatory effects elicited by hypertonic and hypotonic solutions injected into femoral and brachial arteries of dogs. Circulat. Res. 1960, 8, 913.

43. Regan, T. J., P. H. Lehan, D. H. Henneman, A. Behar, and H. K. Hellems. Myocardial metabolic and contractile response to glucagon and epinephrine. J. Lab. clin. Med. 1964, 63, 638.

44. Bagwell, E. E., E. F. Woods, and G. G. Durst, Jr. Influence of reserpine on cardiovascular and sympatho-adrenal responses to cyclopropane anesthesia in the dog. Anesthesiology 1964, 25, 148.

45. Murray, J. F., E. Escobar, N. Jones, and E. Rapaport. The hemodynamic effects of two beta re- 
ceptor-blocking drugs in ariesthetized, intact dogs (abstract). Clin. Res. 1965, 13, 215.

46. Wittels, B., and R. Bressler. Biochemical lesion of diphtheria toxin in the heart. J. clin. Invest. 1964, 43, 630 .

47. Orth, D. N., and H. E. Morgan. The effect of insulin, alloxan diabetes, and anoxia on the ultrastructure of the rat heart. J. Cell Biol. 1962, 15, 509.

48. D'Agostino, A. N. An electron microscopic study of skeletal and cardiac muscle of the rat poisoned by plasmocid. Lab. Invest. 1963, 12, 1060.

49. Ferrans, V. J., R. G. Hibbs, D. G. Weilbaecher, W. C. Black, and G. E. Burch. Alcoholic cardiomyopathy: a histochemical study. Amer. Heart J. 1965, 69, 748.

50. Marinetti, G. V., M. Griffith, and T. Smith. The incorporation of $\left[\mathrm{I}-{ }^{14} \mathrm{C}\right]$ glycerol, $\left[\mathrm{I}-{ }^{14} \mathrm{C}\right]$ acetate and DL- $\left[3-{ }^{14} \mathrm{C}\right]$ serine into the the lipids of rat-heart and liver homogenates. Biochim. biophys. Acta (Amst.) 1962, 57, 543.

51. Olson, R. E. Effect of pyruvate and acetoacetate on the metabolism of fatty acids by the perfused rat heart. Nature (Lond.) 1962, 195, 597.

52. Ballard, F. B., W. H. Danforth, S. Naegle, and R. J. Bing. Myocardial metabolism of fatty acids. J. clin. Invest. 1960, 39, 717.

53. Carlsten, A., B. Hallgren, R. Jagenburg, A. Svanborg, and L. Werkö. Myocardial metabolism of glucose, lactic acid, amino acids and fatty acids in healthy human individuals at rest and at different work loads. Scand. J. clin. Lab. Invest. 1961, 13, 418.

54. Jones, D. P., M. S. Losowsky, C. S. Davidson, and C. S. Lieber. Effect of ethanol on plasma lipids in man (abstract). J. Lab. clin. Med. 1962, 60, 888.
55. Isselbacher, K. J., and N. J. Greenberger. Metabolic effects of alcohol on the liver. New Engl. J. Med. 1964, 270, 351.

56. Woodin, A. M., and A. A. Wieneke. Cellular Injury. Ciba Symposium. Boston, Little, Brown, 1964, p. 30.

57. Regan, T. J., R. C. Christensen, T. Wada, F. N. Talmers, and $\mathrm{H}$. K. Hellems. Myocardial response to acetyl strophanthidin in congestive heart failure: a study of electrolytes and carbohydrate substrates. J. clin. Invest. 1959, 38, 306.

58. Regan, T. J., in discussion of Conn, H. L., and R. J. Luchi. Cellular basis for regulation of the circulation by digitalis and quinidine. Circulat. Res. 1964, 15 (suppl. 2), 166.

59. Ruegsegger, P., I. Nydick, A. Freiman, and J. S. LaDue. Serum activity patterns of glutamic oxaloacetic transaminase, glutamic pyruvic transaminase and lactic dehydrogenase following graded myocardial infarction in dogs. Circulat. Res. 1959, 7, 4.

60. Regan, T. J., C. B. Moschos, A. B. Weisse, and H. K. Hellems. Left ventricular function and metabolism during development of coronary artery thrombosis. Fed. Proc. 1964, 23, 566.

61. Friedberg, C. K. Diseases of the Heart. Philadelphia, W. B. Saunders, 1956, p. 1039.

62. Hackel, D. B., W. T. Goodale, and J. Kleinerman. Effects of thiamine deficiency on myocardial metabolism in intact dogs. Amer. Heart J. 1953, 46, 883.

63. Regan, T. J. Trans. Ass. Amer. Phycns 1965, in press.

64. Hed, R., C. Lundmark, H. Fahlgren, and S. Orell. Acute myopathy in chronic alcoholism. Acta med. scand. 1962, 171, 585. 